\title{
Celiac Plexus Neurolysis
}

National Cancer Institute

\section{Source}

National Cancer Institute. Celiac Plexus Neurolysis. NCI Thesaurus. Code C116513.

A treatment that involves injection of local anesthetic and alcohol to the celiac plexus, causing temporary degeneration of the nerve fibers. The procedure is performed in an effort to alleviate intractable pain, generally caused by cancer or chronic pancreatitis. 